\title{
Two Cases of Hypersexuality Probably Associated with Aripiprazole
}

\author{
EunJin Cheon', Bon-Hoon Koo ${ }^{\circledR}$, Sang Soo Seo ${ }^{2}$ and Jun-Yeob Lee ${ }^{3}$ \\ ${ }^{1}$ Department of Psychiatry, Yeungnam University College of Medicine, Yeungnam University Medical Center, Daegu, Republic of Korea \\ ${ }^{2}$ Department of Psychiatry, School of Medicine, Kyungpook National University, Daegu, Republic of Korea \\ ${ }^{3}$ Department of Psychiatry, CHA Gumi Medical Center, CHA University, Gumi, Republic of Korea
}

Sexual dysfunction is a common side effect in patients treated with antipsychotics but significant differences exist across different compounds. We report hypersexuality symptoms in two female patients with schizophrenia who were receiving treatment with aripiprazole. The patients experienced more frequent sexual desire and greater sexual preoccupation after taking aripiprazole. We discuss the potential neuro-chemical mechanisms for this and argue that aripiprazole's unique pharmacological profile, partial agonism with high affinity at dopamine D2-receptor, may have contributed to the development of these symptoms.

Psychiatry Investig 2013;10:200-202

Key Words Aripiprazole, Hypersexuality, Dopamine, Partial agonist.

\section{INTRODUCTION}

Recent meta-analysis ${ }^{1}$ showed that sexual dysfunction is a common side effect in patients treated with antipsychotics but significant differences exist across different compounds. Aripiprazole was associated with relatively low sexual dysfunction rates, whereas olanzapine, risperidone and clozapine were associated with higher sexual dysfunction rates. Current evidence suggests that a significant part of sexual dysfunction associated with antipsychotic medication results directly from dopamine antagonism combined with indirect effects of increased serum prolactin concentration..$^{2-4}$

However, researchers have reported hypersexuality occurring in association with antipsychotic medication intake, in patients taking quetiapine ${ }^{5}$ or aripiprazole. ${ }^{6}$ Aripiprazole differs from other currently approved antipsychotic drugs because of its partial agonistic activity at dopamine D2 receptors. It is reported that switching to aripiprazole or the addition of aripiprazole to another antipsychotic regime is asso-

Received: July 18, 2012 Revised: October 10, 2012

Accepted: January 12, 2013 Available online: May 30, 2013

$\triangle$ Correspondence: Bon-Hoon Koo, MD, PhD

Department of Psychiatry, Yeungnam University College of Medicine, 317-1 Daemyeong 5-dong, Nam-gu, Daegu 705-703, Republic of Korea Tel: +82-53-622-3343, Fax: +82-53-629-0256, E-mail: vijnana@chol.com

(a) This is an Open Access article distributed under the terms of the Creative Commons Attribution Non-Commercial License (http://creativecommons.org/licenses/by$\mathrm{nc} / 3.0$ ) which permits unrestricted non-commercial use, distribution, and reproduction in any medium, provided the original work is properly cited. ciated with a reduction in sexual dysfunction.?

Here, we report hypersexuality probably occurring in association with aripiprazole treatments in two female patients with schizophrenia.

\section{CASE}

\section{Case 1}

Ms. A was a 37-year-old female patient with schizophrenia, paranoid type. She has a history of multiple relapses with poor compliance requiring recurrent admissions. She was admitted to our university hospital with delusions of reference and persecution, and risperidone $5 \mathrm{mg}$ /day was administered to her. After one year, she experienced galactorrhea and amenorrhea. Subsequently her medication was changed to 10 $\mathrm{mg}$ /day of aripiprazole, then to $20 \mathrm{mg}$ /day. Her positive symptoms decreased after this dosage increase, but her libido increased within a month after this dosage increase. Her hypersexuality was exhibited by 1 ) demand for daily sexual intercourse, 2) frequent use of online pornography. These behaviors had never been exhibited prior to her aripiprazole therapy. Routine physical examination and laboratory investigations were all within normal limits. We discontinued aripiprazole therapy and prescribed risperidone $0.5 \mathrm{mg} /$ day but the patient was lost to follow-up.

5 months later, Ms A was hospitalized for a psychotic episode with delusion of infidelity. She was treated with quetiap- 
ine $800 \mathrm{mg} /$ day. After two months, she was discharged from our hospital. We have no report of an increased demand for sexual relations on her part, and her delusion of infidelity also disappeared.

\section{Case 2}

Ms B was a 36-year-old female patient diagnosed with schizophrenia about 10 years ago. She had obsessive-compulsive and avoidant personality traits. She had never engaged in sexual relationships or dated. Ms B suffered from persecutory delusions, auditory hallucinations, anxiety, and depressed mood. She has been prescribed haloperidol before and at our outpatient clinic, she had received risperidone $2-9 \mathrm{mg}$ /day and fluoxetine $20-40 \mathrm{mg} /$ day for 7 years. Due to weight gain, her medication was changed to aripiprazole $20 \mathrm{mg} /$ day and fluoxetine $40 \mathrm{mg} /$ day. After this medication change, she exhibited increased sexual urges and activities. For example, she engaged in masturbation and sexual fantasies, and watched pornographic materials more frequently. In addition, she sometimes experienced unprovoked spontaneous sexual urges toward strangers. Her new sexual behaviors made her quite embarrassed and she became anxious and guilty. Per patient's insistence, her medication was changed to risperidone quicklet $6 \mathrm{mg}$ /day and maintained on fluoxetine $40 \mathrm{mg} /$ day. Upon cessation of aripiprazole, her high libido level rapidly subsided to her baseline level.

\section{DISCUSSION}

Decreased libido could be linked to the dopamine receptor antagonism by antipsychotics. ${ }^{3,4}$ Conversely, increased sexual desire, as measured by self-report of fantasies, erections, and activities, has been reported in men treated with dopamine agonists such as L-dopa, amphetamine and pramipexole. ${ }^{8} \mathrm{Al}-$ though testosterone is considered the main mediator of sexual desire in men and women, central nervous system (CNS) dopaminergic and serotoninergic pathways seem to play an important role. In particular, brain dopamine systems (incertohypothalamic and mesolimbic) that link the hypothalamus and limbic system appear to form the core of the excitatory system, while serotonin has clear inhibitory effects on sexuality. ${ }^{9}$

Aripiprazole is the first clinically available atypical antipsychotic drug utilizing partial agonism at the dopamine $\mathrm{D}_{2}$-receptor to achieve an atypical antipsychotic profile. ${ }^{10}$ We assumed aripiprazole's dopaminergic agonistic effects may be associated with hypersexuality of our patients. Rather than shutting down the mesolimbic pathway, partial agonism stabilizes the pathway. It may even provide a modest boost in dopamine activity in areas of the brain where it need to be in- creased. ${ }^{11}$ We presumed that aripiprazole disinhibited formerly suppressed dopaminergic activity at the mesolimbic dopaminergic circuit especially at the nucleus accumbens. According to classical receptor theory, the density of receptors directly influences the intrinsic activity of partial agonists. ${ }^{12}$ Therefore, one would predict that prior neuroleptic exposure would increase the tissue's responsiveness and favor the agonist profile of aripiprazole. ${ }^{13}$ Addition of a partial D2 agonist to hypersensitive dopamine receptors may lead to an enhanced dopaminergic drive at the mesolimbic circuit. Aripiprazole also has $5-\mathrm{HT}_{1 \mathrm{~A}}$ partial agonist and $5-\mathrm{HT}_{2 \mathrm{~A}}$ antagonist properties. ${ }^{14}$ Some evidence suggests that activation of the $5-\mathrm{HT}_{2}$ receptor impairs sexual functioning and stimulation of the $5-\mathrm{HT}_{1 \mathrm{~A}}$ receptor facilitates sexual functioning. ${ }^{15}$ Drugs that have $5-\mathrm{HT}_{1 \mathrm{~A}}$ agonist and $5-\mathrm{HT}_{2 \mathrm{~A}}$ antagonist properties i.e., nefazodone and mirtazapine, have minimal, if any, adverse effects on sexual functioning. ${ }^{16}$ Cyproheptadine, a $5 \mathrm{HT}_{2}$ antagonist has been effective in alleviating antidepressant induced anorgasmia. ${ }^{15}$ On the other hand, evidence from double blind controlled studies demonstrates that aripiprazole is not associated with prolactin elevation. ${ }^{17}$ In summary, these receptor profiles and the lack of hyperprolactinemia may foster a potentially favorable atmosphere for the appearance of hypersexuality. However, further research is needed to understand the exact mechanisms through which aripiprazole might affect sexual function.

In our cases, hypersexuality surfaced among people without histories of sexual indiscretions. The patients experienced more frequent sexual desire and greater sexual preoccupation after taking aripiprazole. In the second case, the hypersexuality completely disappeared within days of the patient discontinuing aripiprazole. However, in the first case, we could not be sure about the exact time at which her hypersexuality symptoms resolved, because of the loss of follow-up and recurrence of psychotic symptoms. Hypersexuality might possibly precipitate the formation of delusion of infidelity. Neither patient experienced a reoccurrence of similar hypersexuality phenomena after ceasing to take aripiprazole.

In conclusion, aripiprazole can enhance sexual desire in patients with schizophrenia. We suggest aripiprazole’s dopaminergic agonistic effects at the mesolimbic circuit especially at nucleus accumbens may be responsible for hypersexuality phenomenon. We also suggest that clinicians take hypersexuality into consideration as an aripiprazole's possible adverse effect because misunderstanding of these complications from the clinician's as well as patient's sides could become a source of marital discord and suffering for the patient.

\section{REFERENCES}

1. Serretti A, Chiesa A. A meta-analysis of sexual dysfunction in psychiat- 
ric patients taking antipsychotics. Int Clin Psychopharmacol 2011; 26:130-140.

2. Cutler AJ. Sexual dysfunction and antipsychotic treatment. Psychoneuroendocrinology 2003;28(Suppl 1):69-82.

3. Haddad PM, Wieck A. Antipsychotic-induced hyperprolactinaemia: mechanisms, clinical features and management. Drugs 2004;64:22912314.

4. Knegtering H, van der Moolen AE, Castelein S, Kluiter H, van den Bosch RJ. What are the effects of antipsychotics on sexual dysfunctions and endocrine functioning? Psychoneuroendocrinology 2003;28(Suppl 2):109-123.

5. Menon A, Williams RH, Watson S. Increased libido associated with quetiapine. J Psychopharmacol 2006;20:125-127.

6. Schlachetzki JC, Langosch JM. Aripiprazole induced hypersexuality in a 24-year-old female patient with schizoaffective disorder? J Clin Psychopharmacol 2008;28:567-568.

7. Kerwin R, Millet B, Herman E, Banki CM, Lublin H, Pans M, et al. A multicentre, randomized, naturalistic, open-label study between aripiprazole and standard of care in the management of community-treated schizophrenic patients Schizophrenia Trial of Aripiprazole: (STAR) study. Eur Psychiatry 2007;22:433-443.

8. Sansone RA, Ferlan M. Pramipexole and compulsive masturbation. Psychiatry (Edgmont) 2007;4:57-59.
9. Pfaus JG. Pathways of sexual desire. J Sex Med 2009;6:1506-1533.

10. Kessler RM. Aripiprazole: what is the role of dopamine D(2) receptor partial agonism? Am J Psychiatry 2007;164:1310-1312.

11. Stahl SM. Dopamine system stabilizers, aripiprazole, and the next generation of antipsychotics, part 1, "Goldilocks" actions at dopamine receptors. J Clin Psychiatry 2001;62:841-842.

12. Hoyer D, Boddeke HW. Partial agonists, full agonists, antagonists: dilemmas of definition. Trends Pharmacol Sci 1993;14:270-275.

13. Koener B, Hermans E, Maloteaux JM, Jean-Jean A, Constant EL. Paradoxical motor syndrome following a switch from atypical neuroleptics to aripiprazole. Am J Psychiatry 2007;164:1437-1438.

14. Grunder G, Kungel M, Ebrecht M, Gorocs T, Modell S. Aripiprazole: pharmacodynamics of a dopamine partial agonist for the treatment of schizophrenia. Pharmacopsychiatry 2006;39(Suppl 1):S21-S25.

15. Meston CM, Frohlich PF. The neurobiology of sexual function. Arch Gen Psychiatry 2000;57:1012-1030

16. Farah A. Relief of SSRI-induced sexual dysfunction with mirtazapine treatment. J Clin Psychiatry 1999;60:260-261.

17. Dossenbach M, Hodge A, Anders M, Molnar B, Peciukaitiene D, Krupka-Matuszczyk I, et al. Prevalence of sexual dysfunction in patients with schizophrenia: international variation and underestimation. Int J Neuropsychopharmacol 2005;8:195-201. 